\title{
EM BUSCA DE UMA FUNDAMENTAÇÃO PARA A TRADUÇÃo DE FILOSOFIA ANTIGA: O ASPECTO HERMENÊUTICO
}

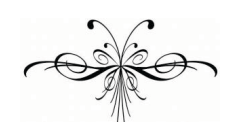

FERNANDO COELHO

\begin{abstract}
Resumo: A tradução dos textos pertencentes à filosofia antiga suscita uma problemática concernente em primeiro lugar aos fundamentos da possibilidade da sua compreensão por leitores do século XXI e, em segundo lugar, aos métodos que podem ser empregados na sua tradução desses textos. Este artigo pretende discutir o primeiro aspecto desse duplo problema, apresentando as diretrizes do método hermenêutico historicista desenvolvido por F. Schleiermacher, chegando finalmente às implicações filosóficas da compreensão do outro e da prática tradutória.
\end{abstract}

\begin{abstract}
The translation of ancient philosophical texts raises a couple of problems concerning, first, the foundations of the possibility of their understanding by the readers of the $21^{\text {st }}$ century and, secondly, the methods that can be used in the translation of them. This article aims to discuss the first aspect of this dual problem within the orientations of the historicist hermeneutic method developed by F. Schleiermacher and getting to the philosophical implications of understanding the other and the practice of translation.
\end{abstract}

$\mathrm{N}$

o trato com obras antigas percebemos que, diversamente do que ocorre com obras da nossa língua-cultura, a compreensão e a interpretação devem ser buscadas metodicamente, isto é, fazse necessário que o tradutor observe um conjunto de regras mais ou menos cientificamente estabelecidas que garantam a objetividade da compreensão e evitem incompreensões. Encontramos na hermenêutica de Friedrich D. E. Schleiermacher uma sistematização de tais diretrizes, que, a despeito da época em que foi desenvolvida e não obstante se considerarem ultrapassados alguns dos seus pressupostos, podem ser empregados ainda hoje nas suas linhas gerais. Alcançada a compreensão objetiva, a tarefa que se põe em seguida é a de conscientizar-se dos elementos lexicais e sintáticos do texto-fonte e das suas relações semânticas, para compor a tradução de tal modo que essa possa ser lida como equivalente do texto original. Além da consciência hermenêutica e linguística necessária à elaboração da tradução, o tradutor deve conhecer o estatuto poético do texto traduzido e o papel transformador que ele próprio, com a sua obra, desempenha na estrutura cultural e linguística da sua comunidade. Contudo, as traduções podem servir a finalidades específicas. O tradutor pode 


\section{FundamENTAÇÃo PARA A TRADUÇÃo DE FILOSOFIA ANTIGA}

objetivar recriar uma obra literária, e então os seus critérios de produção deverão atentar para as características artísticas do texto a ser traduzido. Ele pode, por outro lado, querer apresentar ao leitor as ideias contidas no texto original, preferindo a fidelidade ao estilo, e neste caso teremos uma tradução sensivelmente diferente da que será resultado do exemplo anterior. Nesta ocasião, ater-nos-emos ao problema preliminar da tradução: a compreensão do outro.

Antes que um novo texto em uma nova língua apareça como resultado concreto da tarefa do tradutor, os significados do texto original devem ser reconstruídos. Ao se traduzir, por exemplo, um texto contemporâneo em língua francesa para o português, a sua compreensão precederá à escrita e se dará de modo natural se o tradutor for bom conhecedor de ambas as línguas e participante da cultura das duas comunidades linguísticas. O pertencimento do tradutor ao contexto linguístico-cultural da criação do texto a ser traduzido garante, salvo em casos excepcionais, a compreensão do significado que se verifica nas suas relações interiores. O tradutor pertence, no caso deste exemplo, ao público original a que se destina a obra.

Outro caso - o qual nos interessa particularmente - é o dos textos pertencentes a uma comunidade cultural e linguística distante da do tradutor (e do leitor da tradução). No nosso caso, estamos diante de textos pertencentes a uma civilização extinta, pelo menos na maior parte da sua forma de vida e das suas instituições, e escrito em línguas que, a despeito da sua origem indoeuropeia, guardam diferenças estruturais importantes relativamente ao português. Estamos lidando com textos de cujo público original nos afastamos tanto, linguística e culturalmente, que podemos nos questionar acerca da possibilidade mesma ou das limitações em, primeiramente, compreendê-los e, secundariamente, caso a compreensão seja possível, encontrar na língua portuguesa equivalentes linguísticos que possam compor a sua tradução.

Ao primeiro questionamento devemos encontrar uma resposta que, ao mesmo tempo que fundamente a possibilidade da compreensão de textos do tipo de que tratamos, ofereça também um método prático que permita alcançar os seus significados de modo objetivo; nos termos de Betti:

Somente da parte do intérprete há um verdadeiro compreender, que é mais profundo e mais consciente do que a refletida consciência do autor, pela superioridade que ganha a perspectiva hermenêutica, quando seja o fruto de uma interpretação conduzida segundo os cânones hermenêuticos fundamentais. (1955: 339)

O problema da interpretação dos textos originais de que é composta a Bíblia e dos textos antigos clássicos motivou Friedrich D. E. Schleiermacher, enquanto teólogo e filólogo, a desenvolver as suas reflexões acerca da compreensão e da interpretação textual. Schleiermacher definia a hermenêutica como "a arte de compreender corretamente o discurso de um outro" (Schleiermacher, 2005: 91). É com Schleiermacher que a hermenêutica recebe um tratamento sistemático que a constitui em ciência, ao fornecer um procedimento metódico de compreensão e interpretação em geral, - e já não específico, como era o projeto de Ast, Wolf, Ernesti e Beck, - juntamente com a fundamentação da sua possibilidade. 
Schleiermacher fundamenta a possibilidade da compreensão do discurso alheio na confiança no sadio entendimento humano, cujos princípios universais são comuns tanto ao autor do texto original quanto ao leitor: "a vida humana é uma e a mesma", e "todo discurso, enquanto ato de vida do indivíduo, está sob as regras hermenêuticas universais" (2005: 109). Seu fundamento é, portanto, a unidade do ser humano, a comunidade dos princípios universais que governam as formas de vida e o seu entendimento. Sendo homens, participantes de uma e mesma natureza, podemos, por isso, compreender objetivamente as produções de qualquer outro homem, de qualquer outro tempo, desde que a sua língua e o seu contexto forem conhecidos.

Estabelecido o postulado fundamental, Schleiermacher desenvolve um método geral de compreensão definido como reconstrução histórica e divinatória do conteúdo de um discurso. O fato de os discursos serem produções de linguagem legitima uma vinculação estreita entre a hermenêutica e a gramática:

Uma vez que a hermenêutica deve conduzir à compreensão do conteúdo do pensamento e uma vez que este somente é efetivo por meio da linguagem, a hermenêutica baseia-se na gramática enquanto conhecimento da língua. (2005: 95)

Um discurso particular, em que a linguagem se dá de maneira peculiar, só pode ser compreendido a partir da totalidade da linguagem da qual faz parte. Há um condicionamento do indivíduo por parte da linguagem comum. Schleiermacher estabelece a identidade do falar e do pensar, concluindo que o pensar está limitado às ideias que já tenham uma designação na língua. Naturalmente um novo pensamento pode surgir, mas só pode ser comunicado referindo-se a designações já existentes na linguagem.

A gramática, como parte fundamental da hermenêutica, leva Schleiermacher a estabelecer como critério do seu bom desempenho o talento linguístico, como o recordar-se da língua, o sentido da analogia, da diferença, etc., mas também o talento do conhecimento particular do ser humano, sobretudo dos elementos subjetivos na combinação das ideias. Tais habilidades comporão o método que será descrito adiante.

Tarefa precípua da hermenêutica é o "prevenir-se em relação às dificuldades no reconstruir do discurso e da dinâmica do pensamento." (2005: 103) Parte-se do pressuposto de que o mal-entendido se produz por si mesmo, e só pode ser evitado mediante o esforço consciente e metódico que caracteriza a arte da compreensão. Contudo, Schleiermacher admite que tal tarefa não pode ser cumprida na sua universalidade, pois "as produções de uma língua estranha são sempre fragmentárias para nós.” (2005: 103)

O mal-entendido que deve ser evitado é duplo. (1) Qualitativo: pode dar-se de duas maneiras. Objetivamente, trata-se de uma confusão do lugar de uma parte do discurso com o de outra, ou uma confusão de significado. Subjetivamente, é a confusão que consiste em atribuir a uma expressão relações diferentes das que deu o autor em seu contexto. (2) Quantitativo: também ocorre de dois modos. Objetivamente, é a passagem que assume uma parte do discurso na graduação. Schleiermacher dá o exemplo do grau superlativo. Subjetivamente, é a "força de desenvolvimento de uma parte do discurso, o valor (o acento) que lhe confere o falante." (2005: 114) 


\section{FundAMENTAÇÃo PARA A TRADUÇÃo DE FILOSOFIA ANTIGA}

Para evitar este duplo mal-entendido, a arte da compreensão desenvolve as suas regras positivamente numa fórmula que consiste num "reconstruir 'histórico e divinatório (profético), e (1) objetivo $e$ (2) subjetivo de determinado discurso"" (2005: 114): (1) O reconstruir histórico objetivo consiste em ver o comportamento do discurso na totalidade da linguagem e o saber nela contido como produto da linguagem, enquanto o divinatório objetivo observa como o próprio discurso se torna um fator de desenvolvimento para a linguagem. (2) O reconstruir histórico subjetivo procura saber como o discurso é dado enquanto fato na consciência do autor, e o divinatório subjetivo significa entender como os pensamentos contidos no discurso mantêm a sua atuação no falante e sobre ele.

Para que a arte da compreensão seja efetivada, é preciso que o hermeneuta se coloque na posição do autor, sob o aspecto objetivo e subjetivo. O aspecto objetivo diz respeito à língua em que o discurso foi escrito. É preciso conhecer a língua do autor assim como ele a conhecia. O aspecto subjetivo compreende o conhecimento da vida interior e exterior do autor.

Os aspectos objetivo e subjetivo, porém, são conseguidos pela tarefa da hermenêutica, pois "somente pelos escritos de cada um se pode chegar a conhecer seu acervo linguístico e, dessa forma, seu caráter e suas circunstâncias." (2005: 116) Schleiermacher é consciente do caráter circular do seu método, mas julga-o inevitável e imprescindível:

O acervo linguístico e a história da época de um autor é como o todo a partir
do qual seus escritos precisam ser compreendidos como algo singular; e aquele
todo novamente a partir desses... todo particular só pode ser compreendido a
partir do universal do qual é parte, e vice-versa. E todo saber só é científico se
estiver dessa forma. (2005: 116)

Para Schleiermacher, essas diretrizes metódicas permitem ao hermeneuta "compreender o discurso, primeiramente tão bem e, depois, melhor do que o seu autor" (2005: 115). Não tendo o conhecimento daquilo que se encontra no autor, devemos procurar trazer à consciência o que lhe pode ter permanecido inconsciente.

Schleiermacher dividiu o seu método em duas partes: (1) interpretação gramatical e (2) interpretação psicológica e técnica.

A interpretação gramatical consiste em encontrar o valor de cada parte do discurso, que é em si indefinida: a material, a qual também podemos chamar de léxico; e a formal, que consiste nas relações sintáticas entre os elementos materiais. A definição de cada parte somente poderá ser alcançada a partir do âmbito comum ao autor e ao seu público originário, isto é, o âmbito da sua época, da sua formação e da sua ocupação. Para determinar essas características particulares do texto, é preciso também partir de uma visão geral sobre o todo da escrita:

[O termo] surge, em sua determinação, não a partir de si mesmo, mas de suas circunstâncias, e é somente com essas que nos é permitido ligar a unidade originária do termo, para sempre encontrarmos o correto. (2005: 129)

É possível que nos seja necessário procurar auxílio fora do texto, quando há dificuldade em encontrar o valor correto de um elemento em uma determinada passagem: léxicos e complementações sintáticas (gramáticas) e comentários sobre o texto em questão ou sobre o seu gênero. $\mathrm{O}$ dicionário deverá ser 
utilizado quando houver falta de total clareza acerca do valor linguístico da parte material em análise. Da mesma forma, a consulta à gramática é necessária quando não se tem clareza da relação estabelecida pelos procedimentos sintáticos encontrados no texto.

O sentido dos termos deve ser definido segundo a sua composição com aqueles que os cercam. Isto se aplica tanto aos elementos materiais quanto aos formais, e a determinação do seu sentido deve ser orientada pelo contexto imediato e também a partir de passagens paralelas, em que os termos ou as construções ocorram, podendo estas ser do mesmo autor ou de autores diferentes.

Em se tratando da parte formal, podemos encontrar instâncias que vinculam elementos de enunciados ou os próprios enunciados. A sua determinação se efetiva numa cooperação geral:

1. Em relação ao conteúdo geral atuam primeiramente as ideias principais, em relação aos enunciados diretamente ligados, seus sujeitos e predicados, portanto, o elemento material.

2. No contexto mais próximo age o elemento formal combinado, ou seja, o regime elucida a partícula, e vice-versa.

3. Em sequência, ainda deve-se prestar atenção a fórmulas de ligação coordenadas ou subordinadas.

4. O sentido correto deve efetivar a aplicação; a última determinação sempre precisa partir de um reconstruir desembaraçado. (2005: 145)

Assim, o sujeito e o predicado determinam-se um ao outro, e ambos são, também reciprocamente, melhor determinados por meio de seus adjetivos.

Schleiermacher admite que a interpretação, levada a efeito por esse modo, depende do conhecimento linguístico ainda incompleto, uma vez que ele não é dado perfeitamente de antemão, mas vai-se tornando preciso a cada ocorrência, em cada construção. Tal conhecimento incompleto é, contudo, suficiente para iniciar a interpretação artística, a qual "precisa retroagir no sentido de ampliação e de aperfeiçoamento do conhecimento linguístico.” (2005: 155)

Os enunciados serão, portanto, compreendidos a partir dos seus elementos e das formas em que eles são relacionados. Entretanto, eles também se relacionam entre si e com a unidade do discurso. Aqui será preciso, para a correta compreensão do discurso, distinguir as ideias principais das secundárias, da mesma maneira que será preciso, para compreender a relação entre os enunciados, fazer a distinção entre orações coordenadas e subordinadas. As ideias secundárias são tudo o que não é ideia principal, como meios de apresentação, exemplos, ilustrações. E é de supor que os elementos que compõem a ideia principal continuem sendo empregados no mesmo sentido enquanto se mantiver o mesmo contexto.

No que diz respeito à interpretação psicológica e técnica, ela parte de uma visão geral da obra, isto é, do seu tema, reconhecendo-lhe a unidade da composição na sua importância de mover o autor no seu propósito, ao mesmo tempo evidenciando os traços fundamentais dessa composição, uma vez que é a partir deles que o autor, na sua peculiaridade, se revela. Comunicar o tema é o propósito do autor, e ele o faz de maneira particular, compondo um texto com características próprias, ordenando-o segundo um arranjo que o espelha.

Na composição da sua obra, cada autor é produto e sofre as influências da sua língua, mas, ao mesmo tempo, agindo sobre ela, produz algo novo, "uma 
vez que cada relação ainda não estabelecida entre um sujeito e um predicado é algo de novo" (2005: 200), e imprime assim a sua particularidade, da qual resulta a sua obra. O conhecimento do autor passa pelo conhecimento do âmbito geral da língua, porque aí vemos como ele está sob a sua dependência, como recebe as suas determinações e como ele as retoma e propaga.

Schleiermacher defende a unidade do pensamento e da linguagem: "Pensamento e linguagem, entretanto, convertem-se um no outro e interpenetram-se em toda parte." (2005: 200) Isto conduz à ideia de que o objeto que está contido na composição pode ser compreendido a partir do arranjo linguístico que o constitui. Esse arranjo, contudo, é apenas uma instância de um todo mais amplo que deve ser considerado, sob pena de a compreensão não ocorrer corretamente.

Nesse sentido, a interpretação psicológica deve ser precedida de três elementos. É preciso conhecer de antemão:

a) a maneira por que o objeto se apresentava ao autor;

b) a maneira por que a linguagem era dada ao autor;

c) e o estilo característico do autor.

Schleiermacher estabelece dois métodos interdependentes para a tarefa hermenêutica psicológica, o divinatório e o comparativo. $\mathrm{O}$ divinatório consiste em procurar compreender, de maneira direta, o singular, isto é, o autor e o modo como ele pensou o seu objeto. Para isso é preciso que nos transformemos no outro, no autor, procedimento esse fundamentado na predisposição que cada um de nós tem para nos relacionarmos com todos os outros, e que se efetiva pela comparação com nós mesmos, com o nosso próprio modo de pensar um objeto e de ordenar os elementos de uma composição, desenvolvendo-o linguisticamente. $\mathrm{O}$ método comparativo deve identificar na composição aquilo que é objeto da compreensão tanto no seu aspecto universal, independente das determinações da composição em questão, quanto no seu aspecto particular, tal como foi enunciado pelo autor.

Essa tarefa não pode ser bem desempenhada se não houver uma busca incessante pelo conhecimento mais amplo possível do contexto do autor e da sua composição: "O que deve ser encontrado provisoriamente é a totalidade daquilo que estava à disposição desse escritor.” (2005: 212) A individualidade da época e da comunidade às quais pertence o escritor determina a sua individualidade, de tal modo que a compreensão de uma obra ou do seu autor só é possível a partir da compreensão do contexto da sua época.

Precisando a hermenêutica psicológica, Schleiermacher afirma que ela se compõe de duas tarefas: a (propriamente) psicológica, que se ocupa "do surgimento das ideias a partir do todo dos momentos da vida do indivíduo" (2005: 217), e a técnica, a qual tem por objeto um determinado pensar e a vontade de apresentá-lo.

Quanto à tarefa psicológica, ela se ocupa da unidade da obra enquanto fato na vida do seu autor, isto é, o seu objetivo específico consiste em determinar o modo pelo qual a ideia que é base de todo o desenvolvimento da obra foi alcançada. Será preciso aqui encontrar a relação que a obra tem com a totalidade da vida do autor, mas também com o momento particular da sua criação, e a relação desse momento com todos os outros. 
Dois momentos compõem essa tarefa:

a) o da maior ou menor analogia na forma de combinar as ideias entre o autor e o hermeneuta;

b) o da maior ou menor precisão no conhecimento do material de representação do autor.

Naturalmente, em ambos os momentos, quanto maior for a analogia e a precisão, com mais facilidade o intérprete supera a diferença entre a sua forma de pensar e a do autor.

Quanto à tarefa técnica, essa procura determinar os fatores da produção do texto, a partir da sua forma e conteúdo relativamente à decisão do autor. Essa decisão, esse projeto, tornando-se linguagem, desenvolve-se na escrita. Aqui, a tarefa técnica deve procurar os elementos que evidenciem a ação viva do autor, a sua vontade, da qual derivou o seu texto, pois o texto concreto, que é objeto da análise hermenêutica, é a exteriorização de uma realidade psicológica responsável pela combinação daqueles elementos, combinação que é nova em cada novo texto. Esse procedimento tem a função de evitar a tendência natural que nos leva a imprimir na interpretação uma direção que aponte para as nossas próprias ideias ou para o modo como as combinamos, fazendo com que nos afastemos do propósito original do autor: "Na medida, portanto, em que se pretende compreender perfeitamente, é preciso libertar da relação com suas próprias ideias aquilo que deve ser interpretado." (2005: 253) Para Schleiermacher, a tarefa hermenêutica completa só terá valor se a interpretação de um de texto se der a partir do pensamento do seu autor, se nos livrarmos de nós próprios. Evitando compreender o texto a partir da nossa relação com a composição, devemos procurar conhecer a relação existente entre a composição e a meditação do autor.

O conhecimento dessa relação entre meditação e composição deve impedir-nos de atribuir ao autor pensamentos que não lhe ocorreram, evitando assim enganos que desviariam o hermeneuta do objetivo comunicativo real do escritor, pois a presença ou a ausência de uma concepção no momento da redação da obra pode alterar profundamente a sua significação geral.

O método hermenêutico de Schleiermacher se assenta sobre o postulado de que o seu objeto, isto é, a compreensão das concepções do outro, embora naturalmente dependente da subjetividade do intérprete, tem caráter objetivo. Isto quer dizer que Schleiermacher defende que o seu método, se aplicado com correção, chegará a resultados objetivos que não devem variar significativamente de acordo com cada intérprete. Esse postulado será questionado ao longo da história da hermenêutica, o que, porém, não significa a sua refutação ou o seu abandono; surge um debate acerca da objetividade dos seus resultados, mas sobretudo se colocam questões fundamentais radicalmente novas acerca da compreensão enquanto um determinante existencial e ontológico.

Wilhelm Dilthey, herdeiro conceitual e biógrafo de Schleiermacher, procurou na hermenêutica o fundamento para os métodos das ciências do espírito (Geisteswissenschaften), uma vez que permitia alcançar uma interpretação objetivamente válida das expressões de vida manifestas ao longo da história. Ele estabeleceu a diferença metodológica fundamental entre as ciências do espírito e as ciências da natureza (Naturwissenschaften), cuja abordagem mecanicista e matemática ele acreditava ser incapaz de dar conta da multiplicidade e comple- 


\title{
97 FundamENTAÇÃo PARA A TRADUÇÃo DE FILOSOFIA ANTIGA
}

xidade dos fenômenos humanos. A hermenêutica em Dilthey, portanto, representa um problema epistemológico mais amplo, uma vez que é posta como fundamento de um conjunto de ciências cujo objeto são as expressões que, no seu conjunto, caracterizam a vida humana:

\begin{abstract}
A compreensão das outras pessoas e de suas expressões de vida é baseada tanto na experiência vivida quanto na compreensão de si mesmo e a sua contínua interação. Mas também aqui, não estamos interessados em construção lógica ou análise psicológica; ao contrário, o interesse da nossa análise é epistemológico. Queremos avaliar como a compreensão dos outros contribui para o conhecimento histórico. (Dilthey, 1977: 124)
\end{abstract}

Ao mesmo tempo, é por ela, pela hermenêutica, que se procede a um aprofundamento da nossa consciência histórica, visto que o homem só pode se compreender a si próprio por meio da objetivação da vida, de forma indireta, ou seja, não introspectivamente, mas valendo-se da interpretação presentificadora de expressões de vida que se fixaram na história. Finalmente, Dilthey recusa a perspectiva metafísica idealista, reconhecendo à hermenêutica a capacidade de fornecer meios de compreender as expressões da vida a partir da própria vida, escapando aos esquemas inspirados nas ciências naturais exatas e a sistemas metafísicos que desprezam a lida com a experiência de vida (Dilthey, 1982 passim).

Como Schleiermacher, Dilthey defende a possibilidade de uma transposição real na compreensão do outro, que consiste numa reconstrução tal qual desenvolvida no método exposto acima, pela qual o homem é capaz de uma profundidade de compreensão que não é possível para os objetos das ciências naturais. Contudo, essa compreensão não é absoluta, porque a vida do espírito não o é: é histórica no sentido do seu caráter sempre inacabado. Diferentemente do que ocorre nos objetos das ciências naturais, que se objetivam em categorias estáticas, os objetos das ciências do espírito, as expressões da vida, se dão em momentos complexos, em experiências de totalidade sem a qual o indivíduo não tem lugar e o seu sentido não se verifica.

Emilio Betti, opondo-se a Hans-Georg Gadamer, defende a objetividade da compreensão, afirmando que o objeto mantém-se sempre objeto na interpretação, não importando o papel da subjetividade para o seu desempenho. No objeto há um significado objetivamente verificável, de modo que a sua interpretação objetivamente válida é possível (Betti, 1962: 35). O objetivo de Betti é, portanto, diferente do de Gadamer: ele pensa no historiador enquanto estudioso que observa o seu objeto sem considerar as relações que este objeto tem com a sua vida presente (Betti, 1955 passim).

No seu opúsculo Die Hermeneutik als allgemeine Methodik der Geisteswissenschaften, Betti se mostra próximo de Dilthey na definição do objeto de interpretação: este é uma objetivação do espírito, o qual recebeu, na história, uma forma sensível. E acompanha também Schleiermacher, para quem a interpretação consiste numa reconstrução do significado de formas representativas que o autor concebeu e que objetivou num texto:

(...) As formas representativas, nas quais o espírito se objetivou e os valores espirituais receberam existência fenomênica, constituem uma peculiar combinação da objetividade real, ou seja, com a modificação do mundo sensível, 
sem a qual nem aquelas formas subsistiriam, nem uma existência sensível do valor seria pensável. (Betti, 1955: 53)

É tarefa do intérprete, para que a objetividade seja garantida, reconstruir o significado incorporado no objeto considerado, a partir da sua própria subjetividade, reconhecendo-lhe, contudo, a estranheza. Com isto, fica estabelecida a autonomia do objeto e seu significado em relação ao intérprete. O objeto a ser interpretado não deve, assim como prescreve o método de Schleiermacher, ser destacado do seu contexto: a sua relação com o todo de que faz parte deve estar sempre presente. E, finalmente, o estatuto de objetividade não se perde ao se admitir que há uma atualidade na interpretação, isto é, que o intérprete interpretará sempre a partir de suas próprias experiências (Betti, 1962: passim).

Ao contrário de Dilthey, que propunha uma separação radical entre as ciências da natureza e as ciências do espírito, reclamando para estas a compreensão hermenêutica como fundamento epistemológico, Martin Heidegger, colocando-se numa posição radicalmente nova, faz da hermenêutica uma questão central para o problema do ser: o compreender "é o modo originário de atuar-se do ser-aí (Dasein), que é ser-no-mundo (In-der-Weltsein)... O compreender é o modo de ser do ser-aí enquanto poder-ser (Seinkönnen) e possibilidade." (Gadamer, 1972: 264). Até mesmo o modo pelo qual se verifica o conhecimento dos objetos das ciências naturais deriva do compreender nesse sentido amplo. A interpretação fenomenológica em Heidegger é um método não no sentido da interpretação textual, como vimos em Schleiermacher, mas o modo pelo qual o ser pode ser desvelado: "O sentido metodológico da descrição fenomenológica é interpretação. O lógos da fenomenologia do ser-aí tem o caráter de hermeneúein, através do qual se manifestam ao ser-aí a sua própria compreensão do autêntico sentido do ser e a estrutura do seu próprio ser" (Heidegger, 1967: 37). Para Heidegger, a compreensão, permitindo a cada um a percepção das suas possibilidades de ser, é anterior a qualquer ato de existência, é um fator existencial, que sempre se relaciona com o futuro, mas também está sempre numa estrutura que envolve inescapavelmente o horizonte da situação na qual vive cada um. A compreensão se dá sempre de forma contextualizada e a partir de pressupostos: "A interpretação nunca é a captação sem pressupostos de algo dado anteriormente." (Heidegger, 1967: 150). A manifestação de um objeto se dá no contexto daquilo que deixamos manifestar-se a partir dos pressupostos do nosso mundo.

Assim como em Heidegger, o desenvolvimento da hermenêutica de Gadamer não se caracteriza pela busca de um método que permita a compreensão e a interpretação corretas de um texto, ou pela tentativa de fundamentar epistemologicamente as ciências do espírito. A sua intenção é investigar a possibilidade da compreensão na totalidade da experiência humana. A sua contribuição consiste na contínua elaboração do problema ontológico intuído por Heidegger:

Sobre o pano de fundo desta análise existencial do ser, com todas as suas vastas e ainda inexploradas consequências para os problemas metafísicos gerais, a problemática da hermenêutica das ciências do espírito se apresenta com um aspecto bem diverso. À elaboração deste aspecto novo do problema hermenêutico é dedicado o presente trabalho [Wahrheit und Methode]. (Gadamer, 1972: 264) 
A compreensão é definida por Gadamer como o movimento básico da existência humana, tanto na sua finitude quanto na sua historicidade. Trata-se de um movimento de compreensão que abrange a totalidade da experiência do mundo, englobante e universal, essencialmente dialético, que consiste na interação da autocompreensão de cada um (a partir do seu horizonte) com qualquer coisa que se lhe apresente. Esse horizonte é, porém, composto de juizos prévios ou pressupostos, subjacentes à compreensão em geral. Destarte, não há compreensão sem pressupostos, não é possível deixar o presente em busca de significados do passado: não é possível reconstruir significados passados isentos do presente em que vive o intérprete. A perspectiva do intérprete não se perde: em lugar da reconstituição do passado, verifica-se antes uma fusão de horizontes, pela qual a distância entre o intérprete e o objeto de compreensão é superada.

Para Gadamer "é claro que a reconstrução das condições sob as quais uma obra que nos foi transmitida do passado alcançava a sua finalidade originária é certamente uma operação auxiliar essencial para a compreensão" (Gadamer, 1972: 172). Contudo, permanece a questão fundamental de saber "se isto a que se chega com semelhante ato de reconstruir é, de fato, o significado que procuramos de uma obra, e se é correto definir a compreensão como o ver nela uma segunda criação, a reprodução da produção original (Gadamer, 1972: 162).

Ainda em Wahrheit und Methode, Gadamer discute a questão da interpretação e tradução de textos. Na tradução, "o sentido deve ser mantido, mas, devendo ser compreendido num mundo linguístico diverso, deve ganhar validade de uma outra maneira. Toda tradução é, portanto, já interpretação, pode-se dizer que ela é a consumação da interpretação que o tradutor deu à palavra que se lhe apresentou." (Gadamer, 1972: 387 e 388) No processo tradutório, não há um mero despertar do processo anímico pelo qual se produziu um significado. $\mathrm{O}$ que ocorre é uma reconstituição que tem por guia a compreensão do que está fixado no texto. Nesta reconstituição é ativo o tradutor-intérprete, o qual projeta uma nova luz sobre o texto, resultante do seu horizonte presente. Como o tradutor concretiza a sua interpretação em outro texto, ele deverá revelar como compreendeu os significados do texto original a cada passo, e esta é uma tarefa de grande responsabilidade. É a responsabilidade de fazer falar o texto antes inacessível do outro: "No caso de textos, trata-se de "expressões da vida fixadas permanentemente' e que devem ser compreendidas, e isto significa que um dos interlocutores, o texto, só pode falar através do outro, o intérprete." (Gadamer, 1972: 391).

Fernando Coelho

zeffiretto@gmail.com

Universidade Federal de Santa Catarina 


\section{Referências bibliográficas}

BetTI, Emilio. Die Hermeneutik als allgemeine Methodik der Geisteswissenschaften. Tübingen: 1962

BetTi, Emilio. Teoria Generale della Interpretazione. Milano. Giuffrè: 1955

DiltheY, Wilhelm. Descriptive Psychology and Historical Understanding. Martinus Nijhoff. The Hague: 1977. Translated by Richard M. Zaner and Kenneth L. Heiges

DiltheY, Wilhelm. Gesammelte Schriften V. Stutgart: Teuben; Gottingen: Vandenhoeck und Ruprecht, 1982

GADAMER, Hans-Georg. Gesammelte Werke. Band 1. Hermeneutik I: Wahrheit und Methode: Grundzüge einer philosophischen Hermeneutik. Tübingen. J.C.B. Mohr (Paul Siebeck): 1972

HeIDEGGER, Martin. Sein und Zeit. Tübingen: Max Niemeyer Verlag, 1967

SCHLEIERMACHER, Friedrich D. E. Hermenêutica e Crítica. Trad. De Aloísio Ruedell. Ijuí: Ed. Unijuí, 2005. Vol. I - (Coleção filosofia; 7) 